\title{
High speed toughening-based ceramics grinding mechanism for quality and efficiency
}

\author{
Chongjun WU*, Weicheng GUO*, Zhouping WU**, Kangmei LI*, Beizhi LI* and \\ Steven Y. LIANG*** \\ ${ }^{*}$ College of Mechanical Engineering, Donghua University, 201620, Shanghai, China \\ E-mail: Ikm718@126.com \\ ** Shanghai Spaceflight Manufacture (Group) Co., Ltd, 200245, Shanghai, China \\ ${ }^{* \star *}$ Manufacturing Research Center, Georgia Institute of Technology, 30332, Atlanta, USA
}

Received: 21 March 2019; Revised: 29 June 2019; Accepted: 17 July 2019

\begin{abstract}
Grinding has always been an effective precision machining method for hard-to-machine materials. The knowledge to grinding-induced material properties variation is important for promotion of grinding efficiency and quality, especially for High Speed Grinding (HSG) process. This paper is devoted to investigate the HSG induced material toughening mechanism with Smoothed Particle Hydrodynamics (SPH) simulation method and experimental analysis. In this paper, single grit SPH simulation work is conducted to reveal the indentation and scratching mechanism under different process parameters. Then grinding experiments with grinding force, microscopic topography and surface roughness are given to investigate the grinding wheel speed and chip thickness effects on grinding quality and efficiency. The results show that the $\mathrm{SiC}$ ceramic material gets toughened with extended plastic deformation under a higher indentation speed, which could directly avoid generating brittle fracture cracks after elastic deformation. Combined with the scratching results, it is believed that the transition of material removal mode occurred under different process parameters. Through the grinding experiments, it is suggested to grinding of $\mathrm{SiC}$ ceramics under a higher grinding wheel speed while moderate chip thickness to keep a desired materials removal rate.
\end{abstract}

Keywords : High speed grinding (HSG), Engineering ceramics, Grinding damage, Grinding simulation, Chip thickness

\section{Introduction}

As the typical brittle materials, engineering ceramics has been widely used in different engineering industrial applications, such as bearings, valves and aerospace engineering, etc. This is because that engineering ceramics generally have superior mechanical performance of corrosion, wear, heat resistance and chemical inertness (Wu et al., 2016 and Ding et al., 2019). However, the precision machining of ceramics has always been a big challenge for the inevitable cracks and damages (Yue et al., 2019). High speed grinding process has already been regarded as an efficient precision machining method to achieve better surface finish with lower damages and smaller cracks (Yin et al., 2005 and $\mathrm{Wu}$ et al., 2019). With the increase of grinding wheel speed, the chip thickness will drop down and thus a substantial reduction of grinding force, which will surely improve the grinding workpiece surface quality. Nevertheless, the knowledge to grinding-induced material property variation under HSG process has not yet been fully investigated.

In grinding of ceramics, most of the research works were conducted under conventional wheel speed (Agarwal et al., 2008 and Yang et al., 2017). The grinding damage and crack control have been deemed as the main target. In high speed grinding, Kovach et al.(1993) initially demonstrated that the high speed grinding could be used to machine 
ceramics with dramatically improved surface finish. Later on, more researchers investigate the grinding mechanism (Lin et al., 2015) and modeling of the grinding kinetics (Wu. et al., 2017). All these work has been generally accepted that HSG process could help to bring a better surface quality with high efficiency.

In the meanwhile, the investigation of materials property variation under grinding process has become much more crucial. In HSG process, the grinding wheel linear speed could reach up to higher than $120 \mathrm{~m} / \mathrm{s}$ (Pang et al., 2018), compared with conventional turning or milling of about $10 \mathrm{~m} / \mathrm{s}$ or less. Under this circumstance, the machining strain rate could be higher than $10^{-5} / \mathrm{s}$ (Wang et al., 2016), which will definitely cause a change of materials properties. Wang et al. (2016) simulated the high speed grinding induced damages and cracks in BK7 glass grinding, which concluded that the effect of grinding depth is weaker than wheel speed and a smaller abrasive grain is advantageous to subsurface quality. That was based on traditional finite element simulation method and the change of material properties have not been discussed in detail. Smoothed Particle Hydrodynamics (SPH) has been used as an effective numerical simulation method with mesh-free Lagrangian algoritm, which could remove the mesh tangling issue of large deformation in FEM. Duan et al.(2017) conducted coupling simulation of SPH and FEM to investigate the grinding crack evolution mechanism, which demonstrate the validity of application of SPH in grinding study.

From the above literature review, it could be found that the change of materials properties under HSG process is crucial for investigation of grinding mechanism. This paper is devoted to investigate the high speed toughening mechanism for Silicon Carbide ceramics with SPH grain indentation and scratching analysis. Moreover, the grinding experiments of force, SEM topography and 3D surface roughness will be given to reveal the HSG process effect on surface integrity.

\section{Theoretical Simulation}

\subsection{SPH Theory}

Smoothed Particle Hydrodynamics (SPH) is a typical gridless simulation method, which is on the basis of describing the continuous fluid or solid with interactive particle group that bears different physical variables, such as mass, speed, etc. The SPH method is used to resolve the kinetic equations of particles group and trace the particle's motion trajectory, obtaining the mechanical behaviour of the entire system.

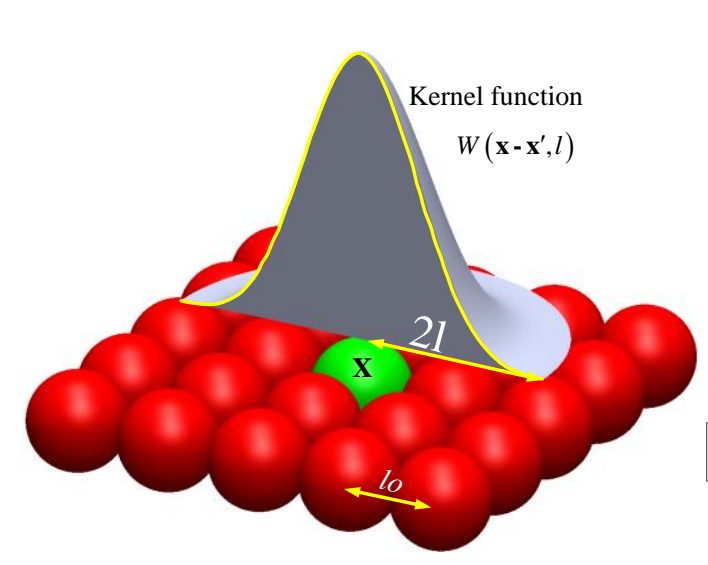

(a)

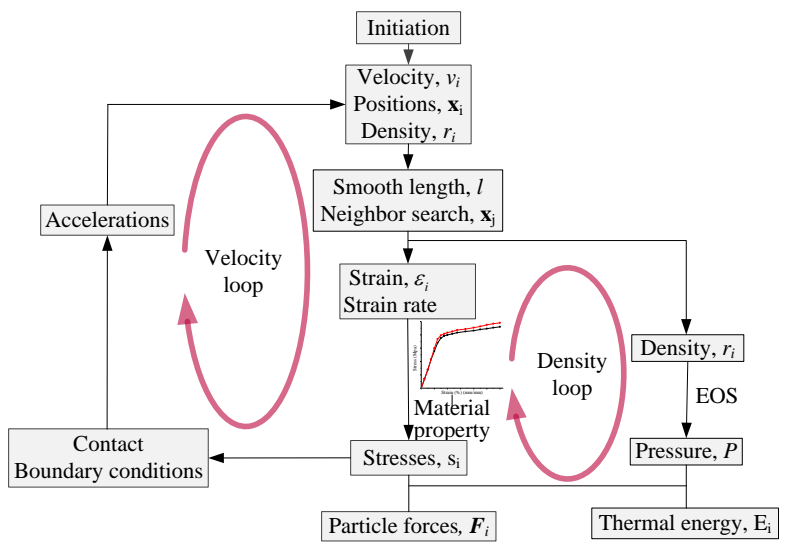

(b)

Fig.1 SPH Theory. (a) The kernel function; (b) Computational flowchart in a single integration step

Fig.1 gives SPH formulation through the kernel function and the typical computational flowchart (Liu et al., 2018). In Fig.1 (a), $x$ is the vector position, the kernel function $\mathrm{W}(x-x, l)$ in Fig.1(a) was defined by the following equations (Limido et al., 2007). 


$$
\begin{aligned}
& \int_{\Omega} W\left(\mathbf{x}-\mathbf{x}^{\prime}, l\right) d \mathbf{x}^{\prime}=1 \\
& \lim _{l \rightarrow 0} W\left(\mathbf{x}-\mathbf{x}^{\prime}, l\right) d \mathbf{x}^{\prime}=\delta\left(\mathbf{x}-\mathbf{x}^{\prime}\right) \\
& W\left(\mathbf{x}-\mathbf{x}^{\prime}, l\right)=0 \quad \text { when }\left|\mathbf{x}-\mathbf{x}^{\prime}\right|>l
\end{aligned}
$$

where $l$ represents the smoothing length which elevates when particles separate each other, and $\Omega$ is the integral space. The kernel based on spline function is widely used for the calculation accuracy for the compact support; the second order infinitesimal dominant error and the continuous second derivative in the integral interpolant. The spline kernel function can be given as (Gingold et al., 1977):

$$
W\left(\mathbf{x}-\mathbf{x}^{\prime}, l\right)=\frac{1}{l^{d}} \theta\left(\frac{\left\|\mathbf{x}-\mathbf{x}^{\prime}\right\|}{l}\right)
$$

where $d$ is the number of space dimensions, $\theta$ is the spline function.

The SPH computation flowchart is developed based on LS-dyna, which could be found in Fig.1(b) with two basic calculation loops. In the initial condition, the velocity $v_{i}$, density $\rho_{i}$ and position $x_{i}$ of particle i are given to calculate the smooth length $l$ with the default value of $1.2 l_{o}$. Then the particle i reaches to the particle $\mathrm{j}$ at the position $x_{j}$ in the range of $2 l$. In velocity loop, the spatial derivatives of position and velocity are used to compute the strain and strain rate between particles $i$ and $j$. In density loop, the density can be renewed based on the relative position and velocity of the particle. At last, the mass, energy and velocity are replaced through the governing equations in the integration step, and thus the force and thermal energy could be obtained.

\subsection{Grain-workpiece interaction model}

Fig.2 gives the 3D grain-workpiece interaction simulation model. In this model, the grain was defined as the rigid triangle diamond grit with a $116^{\circ}$ apex angle and $1 \mu \mathrm{m}$ tip radius. The workpiece is an $8 \times 4 \times 0.5 \mu \mathrm{m}^{3} \mathrm{SiC}$ rectangle meshed by SPH method. The left and bottom surfaces were constrained by the SPH-SYMMETRY-PLAIN(SSP) to avoid the movement of the workpiece in the contact process. The unit system in this simulation is $\mu g-\mu m-\mu s-G P a-m N-n J$. In the simulation, the grain move from the right to left with speed which equals to the grinding wheel speed. Based on the total plastic strain, the erosion criterion is introduced to estimate the material failure due to excessive tensile or compression pressure.

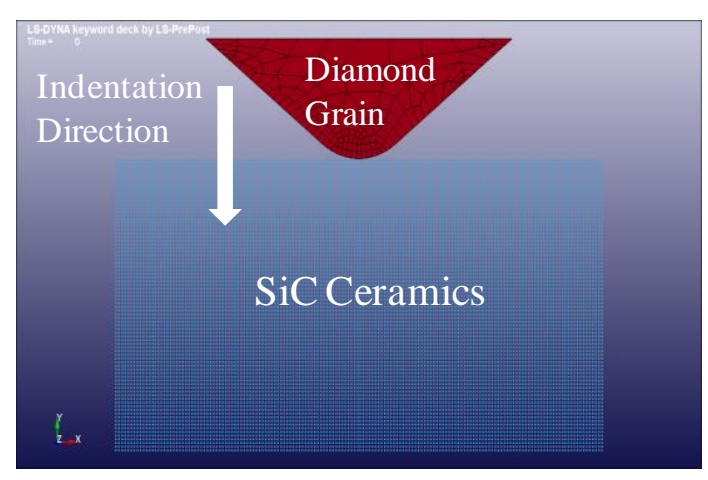

(a) SPH Indentation

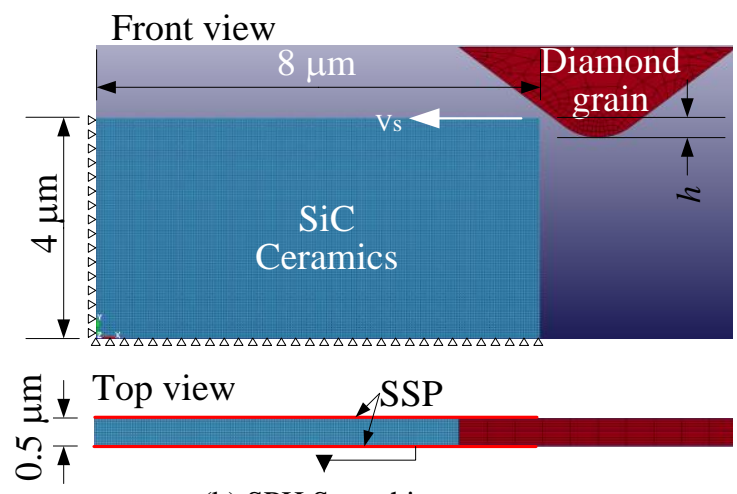

(b) SPH Scratching

Fig.2 Schematic for SPH grain-workpiece engagement model

The simulation is conducted in LS-DYNA. The indentation and scratching simulation will be conducted separately. Moreover, the simulation results are processed in LSPP (LSTC, US). The SiC material and grain parameter are given in Table 1. 
Chongjun Wu, Guo, Zhouping Wu, Kangmei Li, Beizhi Li and Liang, Journal of Advanced Mechanical Design, Systems, and Manufacturing, Vol.13, No.3 (2019)

Table 1 The material parameters (Fang et al., 2005)

\begin{tabular}{ccccc}
\hline Materials & $\begin{array}{c}\text { Density } \\
{\left[\mathrm{kg} / \mathrm{m}^{3}\right]}\end{array}$ & $\begin{array}{c}\text { Young's modulus } \\
{[\mathrm{GPa}]}\end{array}$ & Poisson's ratio & $\begin{array}{c}\text { Shear modulus } \\
{[\mathrm{GPa}]}\end{array}$ \\
\hline $\mathrm{SiC}$ & 3215 & 449 & 0.16 & 193 \\
Diamond & 3560 & 1000 & 0.2 & $/$ \\
\hline
\end{tabular}

\section{Experimental Setup}

The grinding experiments are conducted on the High Speed Grinding machine MGKS1332/H with a linear speed up to $150 \mathrm{~m} / \mathrm{s}$. The grinding experiments setup is given in Fig.3(a). In the experiments, a 5\% water-soluble metal cutting fluid and vitrified diamond wheel $(\Phi 400 \times 22 \times 203.5$, D91 V+2046J1SC C150E) will be used in the experiment. The machine is equipped with a wheel balancing system (SBS model SB 4500), which is used to keep the grinding wheel spindle dynamically balanced under $0.03 \mu \mathrm{m}$ before the grinding experiments. Moreover, in order to keep the wheel grain edge sharp, the wheel was trued by a diamond truing wheel at a speed ratio of 0.8 , cutting depth $2 \mu \mathrm{m}$, wheel speed $80 \mathrm{~m} / \mathrm{s}$ and the transverse feedrate $400 \mathrm{~mm} / \mathrm{min}$. In this work, the grinding wheel is trued by a sintered diamond truing wheel (Winter DS71P-130-1.2), which has a cylindrical diameter of 130mm and top width of $1.2 \mathrm{~mm}$. The detailed grinding experimental conditions are given in Table 2.

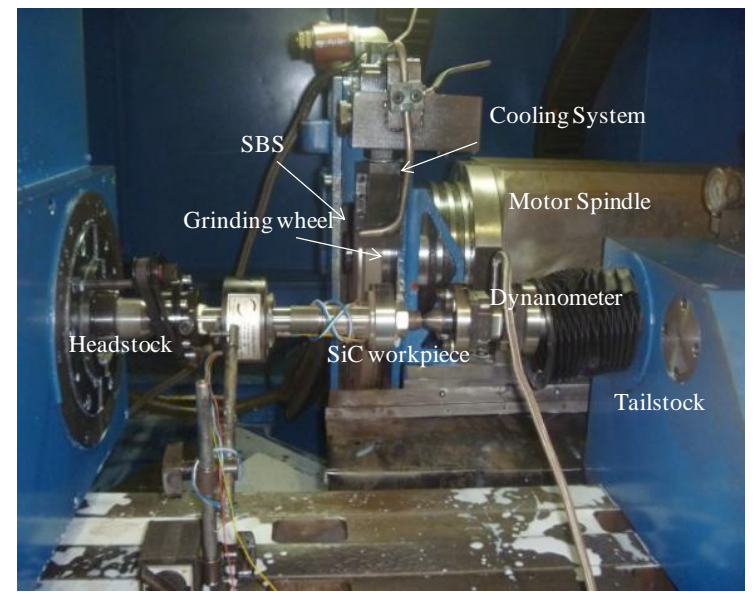

(a)

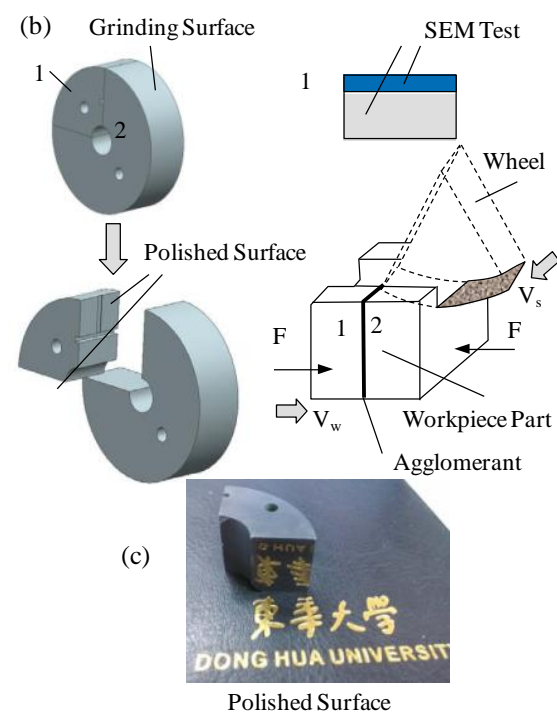

Fig. 3 Experiments setup (a) the grinding platform; (b) workpiece details;(c) polished surface

Table 2 Experimental Conditions

\begin{tabular}{|c|c|c|c|}
\hline Title & Specification & Title & Specification \\
\hline Machine & $\begin{array}{l}\text { CNC cylindrical grinding } \\
\text { machine MGKS1332/H }\end{array}$ & $\begin{array}{l}\text { Wheel balancing } \\
\text { system }\end{array}$ & $\begin{array}{l}\text { SBS Model SB-4500 Below } \\
\qquad 0.03 \mu \mathrm{m}\end{array}$ \\
\hline Wheel & $\begin{array}{l}\text { Vitrified Diamond Wheel D91 } \\
\text { V+ } 2046 \text { J1SC-23 C150 E }\end{array}$ & Coolant & $\begin{array}{l}\text { Water-based emulsion } 5 \% \\
\qquad(10 \mathrm{~L} / \mathrm{min})\end{array}$ \\
\hline Mode & Up grinding & Depth of cut & $1-20 \mu \mathrm{m}$ \\
\hline Wheel speed & $20-140 \mathrm{~m} / \mathrm{s}$ & Workpiece speed & $300-1200 \mathrm{~mm} / \mathrm{min}$ \\
\hline Truing Wheel & Winter DS71P-130-1.2 & & \\
\hline
\end{tabular}

In this experiments, the workpiece material is Reaction-Sintered Silicon Carbide ceramics (RB-SiC), which could 
be found in Fig.3(b). The specimen has a width of $20 \mathrm{~mm}$ and diameter of $60 \mathrm{~mm}$. In Fig.3(b), the workpiece was divided into two parts, the minor part is used to observe the microscopic features with scanning electronic microscope (SEM) test. Before SEM test, the workpiece was polished with diamond paste from $40 \mu \mathrm{m}$ to $0.5 \mu \mathrm{m}$ and ultrasonic bathed in acetone liquid for 15 minutes. The SEM observations were conducted on QUANTA 250 from Czech. The surface roughness was measured through a 3D Bruker Nano Surface white light interferometer (Npflex).

\section{Results and discussions}

\subsection{Indentation Toughening}

Fig.4 is the indentation force under different indentation depth at a quasi-static indentation of $1 \mathrm{~m} / \mathrm{s}$. It can be found that there are three typical deformation stages: the elastic stage P2 (Point $R_{1}$ to R2), plastic stage P3 (Point $R_{2}$ to $\mathrm{R}_{3}$ ) and brittle fracture failure stage $\mathrm{P} 4$ (Point $\mathrm{R}_{3}$ to the end). In this indentation process, the workpiece broke after a short elastic and plastic deformation, which is a common phenomenon in compression of brittle materials.

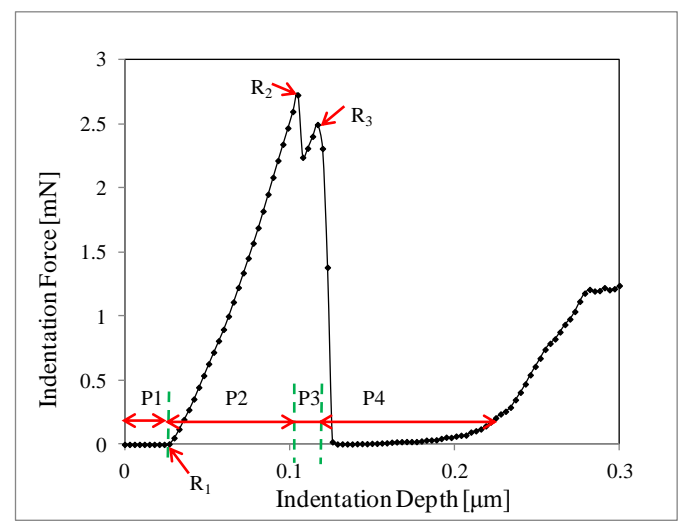

Fig.4 Indentation force under different indentation depth at indentation speed of $1 \mathrm{~m} / \mathrm{s}$

(P1:Before contact,P2:Elasttic stage, P3:Plastic stage, P4:Brittle fracture failure)
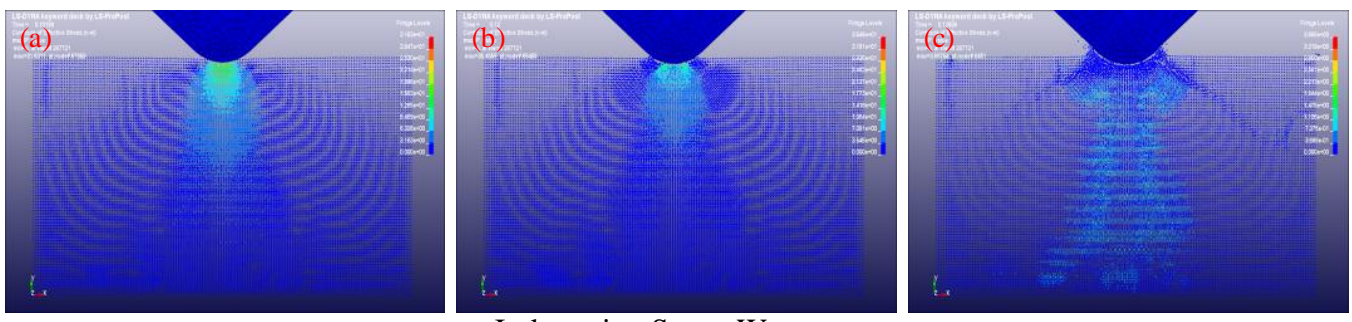

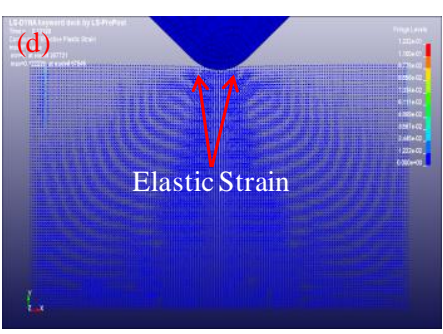

$\mathrm{L}=0.105 \mu \mathrm{m}$

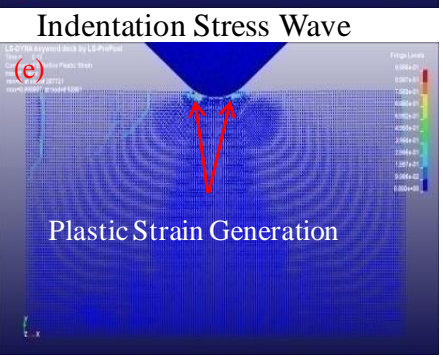

Indentation Strain Variation

$\mathrm{L}=0.120 \mu \mathrm{m}$

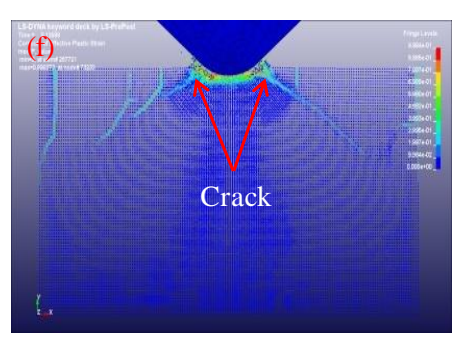

$\mathrm{L}=0.126 \mu \mathrm{m}$

Fig.5 Crack generation under different indentation depth $\mathrm{L}$ at indentation speed of $1 \mathrm{~m} / \mathrm{s}$

Fig.5 gives the corresponding indentation process of P3 plastic deformation stage in Fig.4, which reflect the crack generation process at different indentation depth. In this Figure, (d), (e) and (f) are the strain variation in P3 stage, the strain color under the indentor could reflect the possible elastic and plastic strain. It could be found that the stress wave 
in Fig.5(a) is annularly-distributed under the grain when the depth is $0.105 \mu \mathrm{m}$, typical wave feature could be found and elastic strain under the indentor dominates in Fig.5(d). When the depth is at $0.120 \mu \mathrm{m}$, the material is enduring the plastic deformation and plastic strain occurs under the indentor in Fig.5(e). Furthermore, the stress wave starts to scatter in Fig.5(b). However, when the indentation depth reaches up to $0.126 \mu \mathrm{m}$, the fracture crack generates to both sides in Fig.5(f)., accompanying with dispersive stress wave in Fig.5(c).

In order to reveal different material properties in indentation process, the force change under different indentation speed and depth are given in Fig.6(a). It can be found that the force characteristics vary with the increase of indentation speed. When the indentation speed is $1 \mathrm{~m} / \mathrm{s}$, the $\mathrm{SiC}$ material broke after short elastic deformation and plastic deformation. However, with the increase of indention speed to $10 \mathrm{~m} / \mathrm{s}$, the plastic deformation was prolonged to a deeper indentation depth before the indention force drops down drastically. When the indentation speed s comes to $80 \mathrm{~m} / \mathrm{s}$ or $140 \mathrm{~m} / \mathrm{s}$, the plastic deformation occurs at a deeper indention depth even than the elastic deformation, which becomes the main material deformation and the indentation force wavelike rises up. It is obvious that the material gets toughened under higher indentation speed. It can also be found that the indentation force varies at large differences under different indentation speeds. In the one hand, this could possibly be ascribed to the nature of brittle materials, which causes inner cracks or damages randomly and thus the fluctuated force produced. In another, when the indentor puts on the material, the materials will experience a short cycle of elastic and plastic deformation (especially in high indentation speed), which could help to toughen the materials with more plastic deformation and prominent force variation.
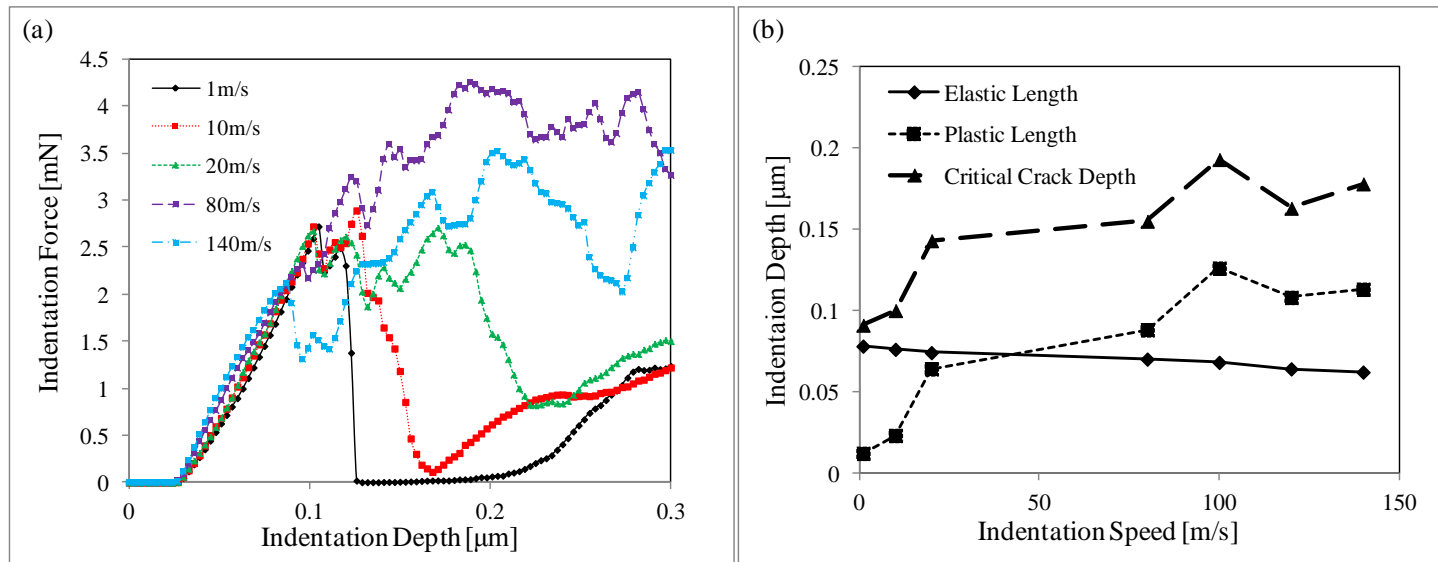

Fig.6 (a) Indentation force variation under various indentation speed and depth;

(b) Different deformation stage under various indentation speed and depth

Fig.6(b) is the variation of elastic length, plastic length and critical crack depth with the increase of indentation speed. Here, the critical crack depth represents the critical indentation depth that generates the fracture crack. The elastic length and plastic length matches the P2 and P3 stages in Fig.4. It can be found that the plastic length increases with the increase of indentation speed, compared with a slight reduction of elastic deformation. Moreover, the critical indentation depth increases substantially with the increase of speed, which is brought by the increase of the plastic deformation in high indentation speed.

From the above analysis of grain indentation, it could be concluded that SiC ceramic material gets toughened and more plastic deformation occurs under a higher indentation speed. This implies a transition of material removal mechanism happens when the indentation speed increase form quasi-static to high speed of $140 \mathrm{~m} / \mathrm{s}$.

\subsection{Grit Scratching Mechanism}

In order to match the real grain-workpiece interaction process, a single grit scratching simulation was conducted to study the scratching force and topography. In grinding of brittle materials, it is believed that the material will be removed in a ductile mode when the maximum chip thickness $h_{m}$ is lower than a critical chip thickness (Bifano et al., 1991). The critical value $d_{c}$ is given as: 


$$
d_{c}=\beta\left(\frac{E}{H_{V}}\right) \cdot\left(\frac{K_{1 C}}{H_{V}}\right)^{2}
$$

where $\beta$ is a constant determined by material properties. $E, H_{V}$ and $K_{I C}$ are, respectively, the elastic modulus, the hardness and fracture toughness. The maximum undeformed chip thickness is written as follows (Wu et al., 2016):

$$
h_{\mathrm{m}}=\left(\frac{3}{C_{d} \cdot \tan (\theta)} \cdot \frac{V_{w}}{V_{s}} \cdot \sqrt{\frac{a_{p}}{d_{e}}}\right)^{\frac{1}{2}}
$$

where $C_{d}$ is the active abrasive grits number in unit area. $a_{p}$ is the depth of cut $V_{s}$ and $V_{w}$, respectively, wheel speed and workpiece speed. $d_{e}$ represents the equivalent diameter, which can be calculated through $1 / d_{e}=1 / d_{s}+1 / d_{w}, d_{s}$ and $d_{w}$ are the diameter of grinding wheel and workpiece. In this paper, $C_{d}$ was calculated as (Xu et al., 1997):

$$
C_{d}=4 \chi /\left\{d_{g}^{2}(4 \pi / 3 \omega)^{2 / 3}\right\}
$$

where $d_{g}$ is the equivalent spherical diameter of abrasive grain, the abrasive diameter in this manuscript has an average of $91 \mu \mathrm{m}$. $\omega$ and $\chi$ are, respectively, the volume fraction of diamond grain and the proportion of grits that are actively engaged in the cutting process. The grinding wheel in this paper has a concentration density of 150, thus the volume fraction $\omega$ is 0.375 (Malkin et al., 1989). Moreover, it is assumed that $\chi$ is $1 / 2$ (Agarwal et al., 2013).

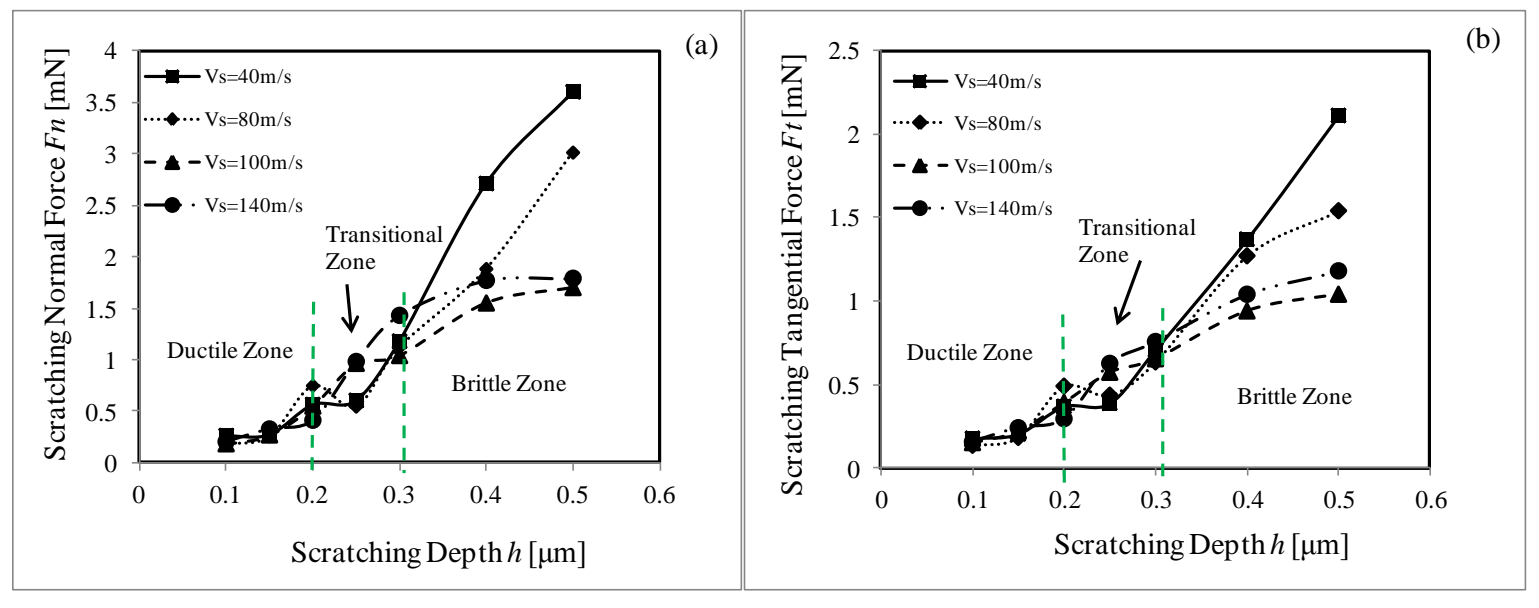

Fig.7 Scratching force analysis

Fig.7 shows the variation of normal (a) and tangential (b) force under different scratching depth and speed. It can be found that the increase of scratching depth causes an increase of both of the forces, this is quite understandable for the increase of grain-workpiece interaction depth. However, when the scratching speed increases from $40 \mathrm{~m} / \mathrm{s}$ to $140 \mathrm{~m} / \mathrm{s}$, the force does not increase with the same trend. When the scratching depth is below $0.2 \mu \mathrm{m}$, the forces keep low almost at the same value. While when the depth comes to $0.2 \mu \mathrm{m}$ to $0.3 \mu \mathrm{m}$, the forces fluctuate in a certain amplitude range. When the depth is higher than $0.3 \mu \mathrm{m}$, the forces increase toward different directions. The force curve slope for 40 and $80 \mathrm{~m} / \mathrm{s}$ shows a higher slope value, while the curve for higher speed value of 100 and $140 \mathrm{~m} / \mathrm{s}$, the slope value is much smaller. This exactly proves that the increase of scratching speed have caused a transition of material removal mode. From the equation (5) and (6), it can be concluded that ductile removal mode at low scratching depth has changed to brittle removal mode with higher scratching depth during the increase of scratching speed from 40 to $140 \mathrm{~m} / \mathrm{s}$. 


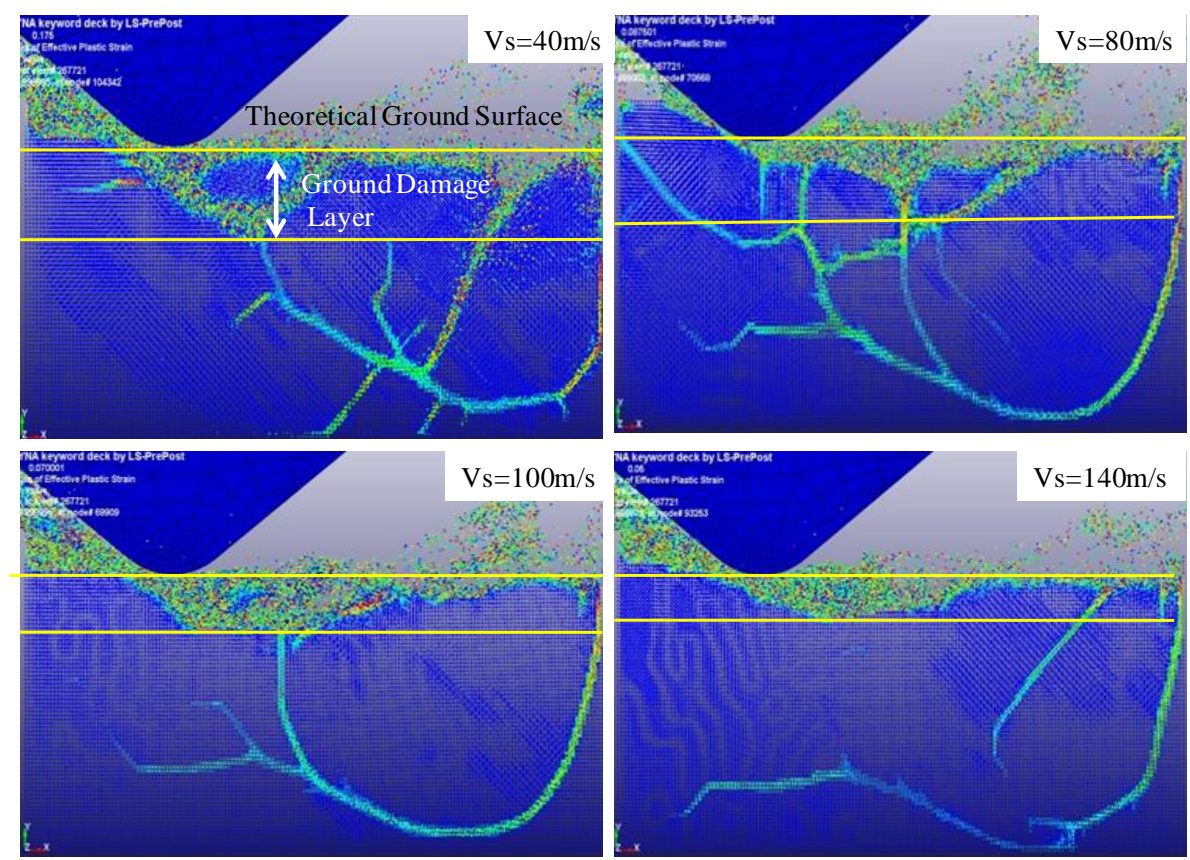

Fig.8 Scratching topography under different scratching speed

Fig. 8 shows that the increase of scratching speed is beneficial to the surface damage control. In this figure, the scratch depth keeps constant at $0.5 \mu \mathrm{m}$. When the speed is $40 \mathrm{~m} / \mathrm{s}$, the workpiece surface is mainly uneven cracks and cracks evolve to the inner part of the material with a large damage layer. With the increase of scratching speed, massive cracks vanished and damage layer gets lower. Deep cave becomes to a relative minor cave and flat surface is generated at $140 \mathrm{~m} / \mathrm{s}$ of scratching speed. Thus, it can be concluded that the increase of scratching speed help to control the surface damage. This could be explained from the indentation simulation, the increase of speed toughens the material, which increases the ability to prevent the crack generation and evolution.
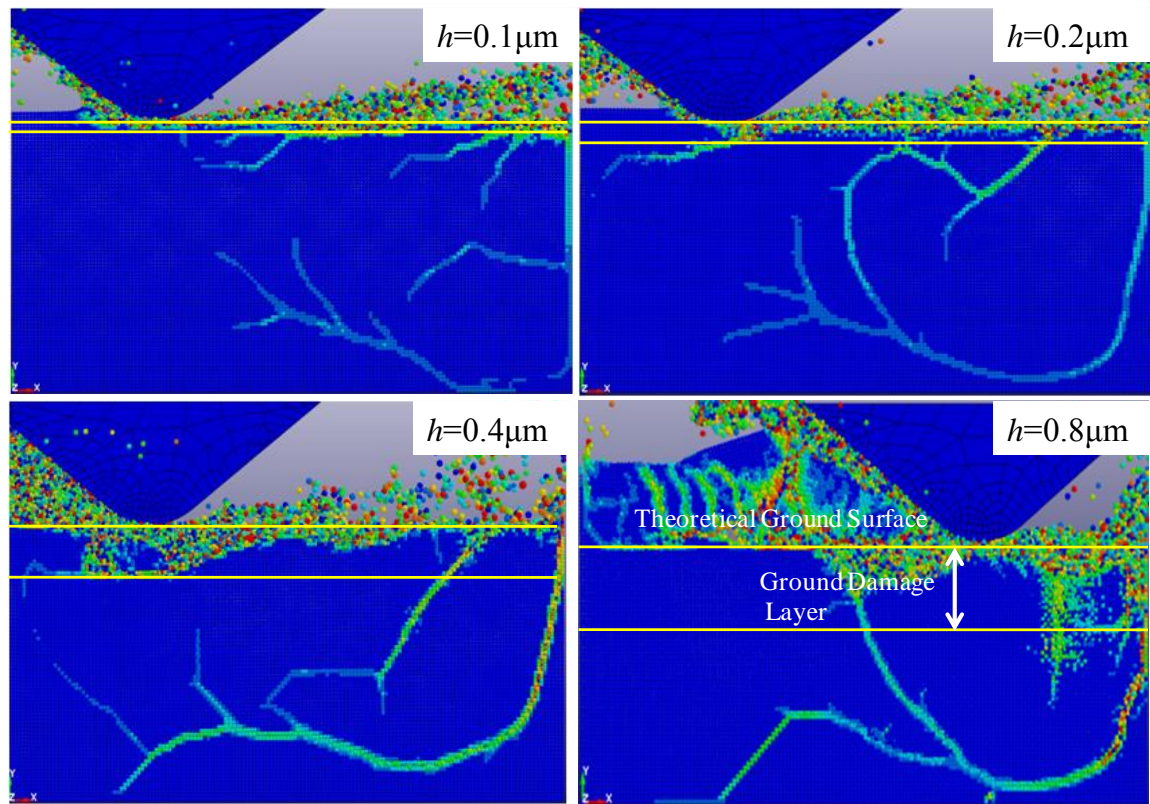

Fig.9 Scratching topography under different scratching depth

Fig.9 shows the scratching depth effect on the workpiece surface topography. In this figure, the scratching speed keeps constant at high speed of $140 \mathrm{~m} / \mathrm{s}$. It can be found that when the scratching depth is $0.1 \mu \mathrm{m}$, the surface damage layer is very shallow with crack-free surface. Moreover, the crack does not evolve to the inner material. However, with the increase of the scratching depth, the workpiece surface was scratched to a larger damage layer. When it is at $0.8 \mu \mathrm{m}$, 
huge chips were produced and the subsurface cracks started to evolve to the inner material. The workpiece surface is featured by the peel-off of the cracks. This could also be explained by the increase of indentation depth, which causes the generation of cracks and material damage, thus the material strength gets weak. In another word, the decrease of scratching depth could toughen the material to prevent surface damage.

\subsection{Grinding Experiments for Ceramics}

The grinding experiments are conducted to investigate the effect of grinding process parameters on the force, surface and subsurface damage and surface roughness, which is intended to explain the high speed grinding integrity control. In Fig.10, the average grinding forces on a single grain are depicted. Table 3 is the process parameters for Fig.10, No.1-5 is used for Fig. 10(a) and No.5-9 for Fig.10 (b). It could be found from Fig.10(a) that both the normal and tangential force linearly decrease with the increase of wheel speed. However, the forces increase with the increase of chip thickness in Fig.10(b). In grinding process, the increase of the wheel speed will surely increase the grain-workpiece frequency, which will reduce the grinding forces. Nevertheless, the increase of chip thickness will exponentially increase the material removal rate $\left(Q^{\prime}{ }_{w}=a_{p} * V_{w}\right)$, which could be determined from equation (6). Therefore, the forces increase at a large slope.

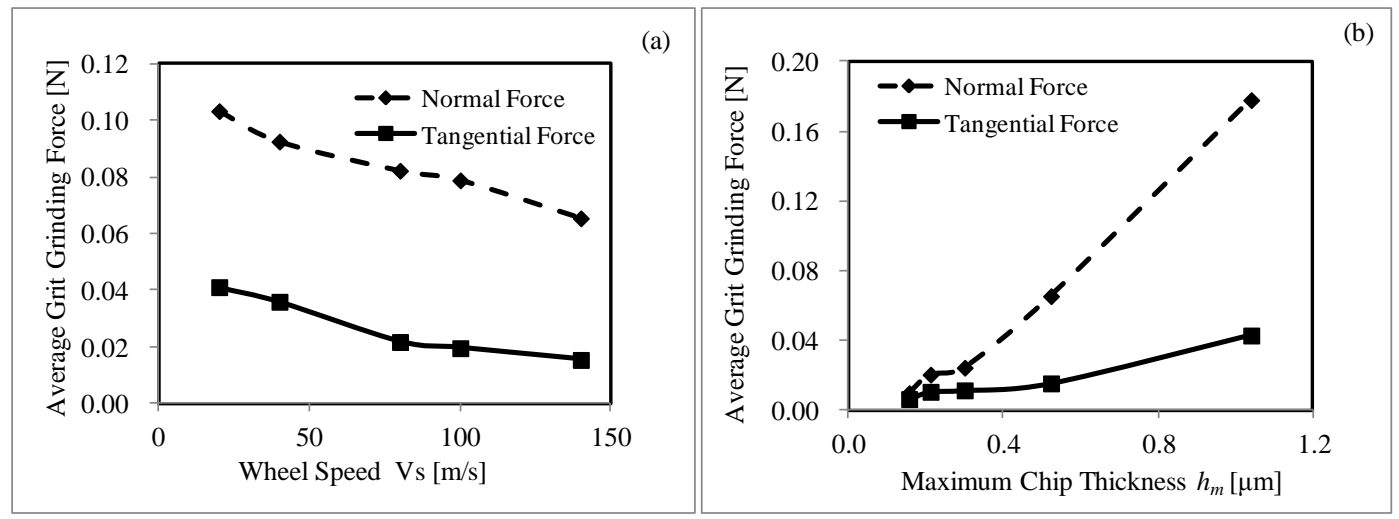

Fig.10 Grinding force variation under different wheel speed and chip thickness

Table 3 Grinding process parameter for efficiency

\begin{tabular}{cccccc}
\hline No. & $\begin{array}{c}\text { Depth of Cut } \\
a_{p}[\mu \mathrm{m}]\end{array}$ & $\begin{array}{c}\text { Workpiece Speed } \\
V_{w}[\mathrm{~m} / \mathrm{s}]\end{array}$ & $\begin{array}{c}\text { Wheel Speed } \\
V_{s}[\mathrm{~m} / \mathrm{s}]\end{array}$ & $\begin{array}{c}\text { Maximum Chip } \\
\text { Thickness } h_{m}[\mu \mathrm{m}]\end{array}$ & $\begin{array}{c}\text { Material Removal } \\
\text { Rate } Q^{\prime}{ }_{W}\left[\mathrm{~mm}^{3} / \mathrm{mms}\right]\end{array}$ \\
\hline 1 & 0.2 & 0.1 & 20 & 0.52 & 0.02 \\
2 & 0.08 & 0.1 & 40 & 0.52 & 0.08 \\
3 & 3 & 0.1 & 80 & 0.52 & 0.3 \\
4 & 5 & 0.1 & 100 & 0.52 & 0.5 \\
5 & 9.2 & 0.1 & 140 & 0.52 & 0.92 \\
6 & 3 & 0.016 & 140 & 0.16 & 0.048 \\
7 & 1 & 0.05 & 140 & 0.21 & 0.5 \\
8 & 1 & 0.1 & 140 & 0.31 & 0.1 \\
9 & 5.2 & 0.525 & 140 & 1.04 & 2.73 \\
\hline
\end{tabular}

In table 3, the material removal rate $Q^{\prime}{ }_{w}$ is calculated to reflect the grinding efficiency. Fig.11 shows the grinding speed effect on the surface topography, subsurface damage layer and surface roughness. In this Figure, the process parameter is No.1, 3 and 5 in Table3, the maximum chip thickness keeps constant at $0.52 \mu \mathrm{m}$, while the speed increase from $20 \mathrm{~m} / \mathrm{s}$ to $140 \mathrm{~m} / \mathrm{s}$. It can be found from Fig. 11 that the increase of wheel speed cause a reduction of surface crack cave $\mathrm{A}$ and the increase of surface plastic strips $\mathrm{B}$. While for the subsurface damage, the huge crack cave $\mathrm{C}$ and chipping across the SiC grain $\mathrm{D}$ can be found. With the increase of wheel speed, the huge crack vanished and 
subsurface damage layer decrease from $95 \mu \mathrm{m}$ at $10 \mathrm{~m} / \mathrm{s}$ to $41 \mu \mathrm{m}$ of $140 \mathrm{~m} / \mathrm{s}$. For the 3D surface roughness, it is reduced from $0.457 \mu \mathrm{m}$ of $20 \mathrm{~m} / \mathrm{s}$ to $0.187 \mu \mathrm{m}$ of $140 \mathrm{~m} / \mathrm{s}$. For Fig. 11 , the material removal rate $Q^{\prime}{ }_{w}$ immensely increases from $0.02 \mathrm{~mm}^{3} / \mathrm{mms}$ to $0.92 \mathrm{~mm}^{3} / \mathrm{mms}$. Therefore, it could be concluded that the increase of wheel speed could help to facilitate the plastic deformation and reduce unpleasant cracks, bringing about the promotion of surface roughness with enormous promotion of grinding efficiency.
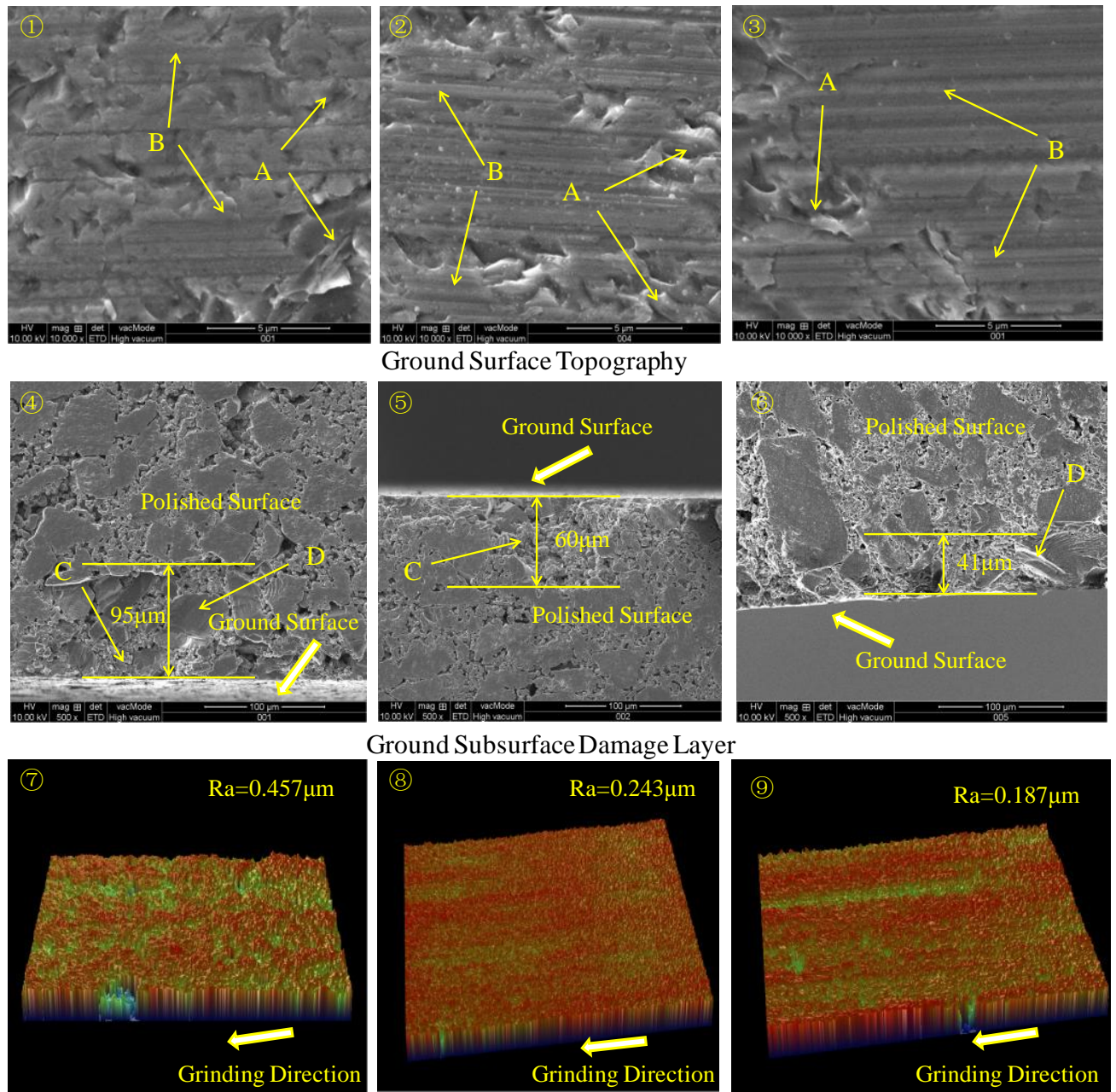

Ground Subsurface Damage Layer
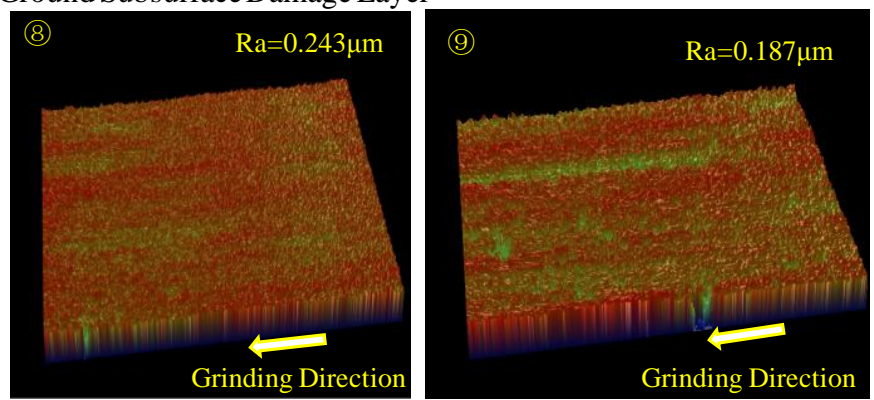

$\mathrm{Vs}=20 \mathrm{~m} / \mathrm{s}, h_{m}=0.52 \mu \mathrm{m}$

Ground Surface Roughness

$$
\mathrm{Vs}=80 \mathrm{~m} / \mathrm{s}, h_{m}=0.52 \mu \mathrm{m}
$$

$\mathrm{Vs}=140 \mathrm{~m} / \mathrm{s}, h_{m}=0.52 \mu \mathrm{m}$

Fig.11 Grinding integrity with the change of wheel speed

Fig.12 shows the effect of maximum chip thickness $h_{m}$ on grinding quality. It could be found that with the increase of $h_{m}$, lesser plastic strips and more fracture cracks were produced. In the meanwhile, the subsurface damage layer increases from $23 \mu \mathrm{m}$ at $h_{m}$ of $0.31 \mu \mathrm{m}$ to $41 \mu \mathrm{m}$ of $0.52 \mu \mathrm{m}$ and finally $97 \mu \mathrm{m}$ of $1.04 \mu \mathrm{m}$. For the workpiece surface roughness, it increases from $0.165 \mu \mathrm{m}$ at $h_{m}$ of $0.31 \mu \mathrm{m}$ to $0.187 \mu \mathrm{m}$ of $0.52 \mu \mathrm{m}$ and finally $0.255 \mu \mathrm{m}$ of $1.04 \mu \mathrm{m}$. Moreover, the materials removal rate ${ }^{\prime}{ }_{W}$ increases from $0.1 \mathrm{~mm}^{3} / \mathrm{mms}$ to $2.73 \mathrm{~mm}^{3} / \mathrm{mms}$. When the wheel speed keeps constant, it could be found from equation (6) that the increase of chip thickness is mainly brought by elevation of workpiece speed or depth of cut, either of them will bring out an increase of the materials removal rate $Q{ }^{\prime}{ }_{W}$. Thus the surface quality deteriorates with larger subsurface damage layer, worse surface topography with fracture cracks. It is generally suggested to conduct high speed grinding of ceramics at a higher grinding speed and moderate chip thickness, which could help improve grinding quality with desired machining efficiency. 

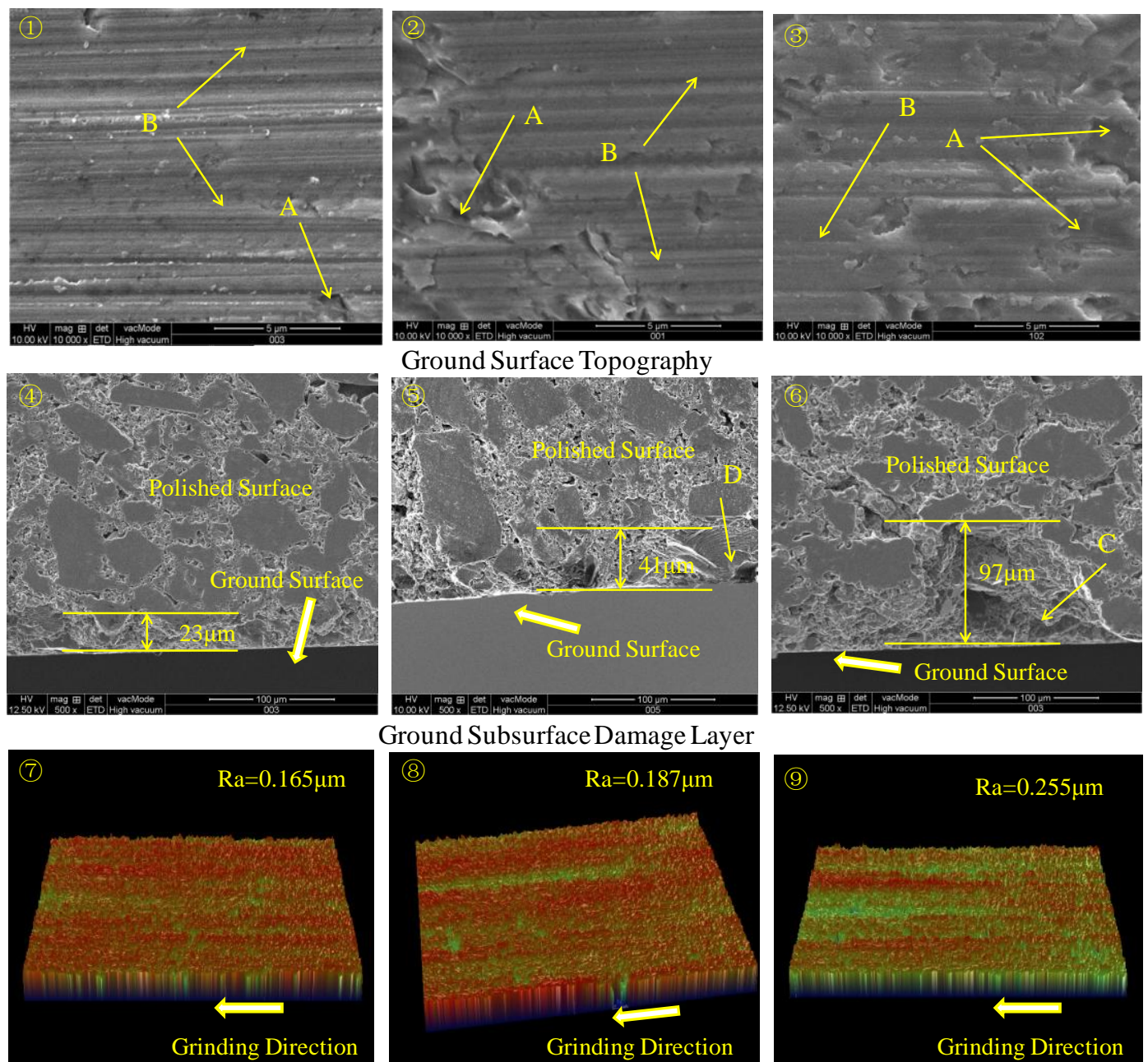

Ground Subsurface Damage Layer
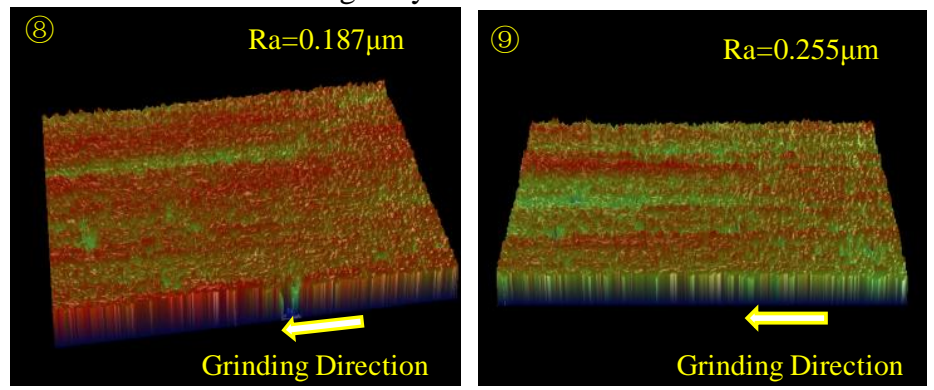

Ground Surface Roughness

$$
\mathrm{Vs}=140 \mathrm{~m} / \mathrm{s}, h_{m}=0.31 \mu \mathrm{m} \quad \mathrm{Vs}=140 \mathrm{~m} / \mathrm{s}, h_{m}=0.52 \mu \mathrm{m} \quad \mathrm{Vs}=140 \mathrm{~m} / \mathrm{s}, h_{m}=1.04 \mu \mathrm{m}
$$

Fig.12 Grinding surface integrity with the change of chip thickness

\section{Conclusions}

This paper investigated the HSG induced material toughening mechanism with Smoothed Particle Hydrodynamics (SPH) simulation method and experimental analysis. The single grit SPH simulation work was conducted to analyse the indentation and scratching mechanism under different process parameters. High speed grinding experiments were exploited to investigate the grinding wheel speed and chip thickness effects on grinding quality and efficiency.

The grain indentation simulation revealed that $\mathrm{SiC}$ ceramic material was toughened under HSG process with more plastic deformation and better crack prevention ability. The scratching results indicate a transition of material removal mode between ductile and brittle removal when the process parameters change. From the grinding experiments, it could be concluded that the increase of wheel speed and decrease of chip thickness could help to facilitate the plastic deformation and reduce unpleasant cracks, thus the promotion of surface roughness with enormous promotion of grinding efficiency. It is generally suggested to conduct high speed grinding of ceramics at a higher grinding speed and moderate chip thickness, which could help improve grinding quality with desired machining efficiency. 


\section{Acknowledgements}

This work is supported by the Fundamental Research Funds for the Central Universities (NO.2232018D3-14), Shanghai Sailing Program (19YF1401400) and China Postdoctoral Science Foundation (2018M630384). The authors wish to record their gratitude for their generous supports.

\section{References}

Agarwal, S. and Rao, P.V., Predictive modeling of force and power based on a new analytical undeformed chip thickness model in ceramic grinding, International Journal of Machine Tools \& Manufacture, Vol.65, No.2(2013), pp.68-78.

Agarwal, S., and Rao, P.V., Experimental investigation of surface/subsurface damage formation and material removal mechanisms in SiC grinding, International Journal of Machine Tools \& Manufacture, Vol.48, No.6(2008), pp.698-710.

Bifano, T.G., Dow, T.A. and Scattergood, R.O., Ductile-regime grinding: A new technology for machining brittle materials. Journal of Engineering for Industry-Transactions of the ASME, Vol.113, No.2(1991), pp.184-189.

Ding, Z.S., Sun, G.X., Jiang, X.H., Guo, M.X. and Liang, S.Y., Predictive Modeling of microgrinding force incorporating phase transformation effects. Journal of Manufacturing Science and Engineering-Transactions of the ASME, Vol.141, No.8(2019), 081009, DOI: 10.1115/1.4043839.

Duan, N., Yu, Y., Wang, W. and Xu, X., SPH and FE coupled 3D simulation of monocrystal SiC scratching by single diamond grain, International Journal of Refractory Metals \& Hard Materials, Vol.64(2017), pp.279-293.

Fang, F.Z., Wu, H. and Liu, Y.C., Modelling and experimental investigation on nanometric cutting of monocrystalline silicon, International Journal of Machine Tools \& Manufacture, Vol.45 (2005), pp.1681-1686.

Gingold, R.A. and Monaghan, J.J., Smoothed particle hydrodynamics - theory and application to non-spherical stars, Monthly Notices of the Royal Astronomical Society, Vol.181 (1977), pp.375-389.

Kovach, J.A., Blau, P.J., Malkin, S., Srinivasan, S., Bandyopadhyay, B. and Ziegler, K., Feasibility investigation of high-speed, low damage grinding for advanced ceramics, Society of Manufacturing Engineers, Cincinnati, Ohio(1993), pp.1-16.

Limido, J., Espinosa, C., Salauna, M. and Lacome, J.L., SPH method applied to high speed cutting modelling, International Journal of Mechanical Sciences, Vol.49 (2007), pp.898-908.

Liu, Y., Li, B.Z., Wu, C.J., Kong, L.F. and Zheng, Y.H., Smoothed particle hydrodynamics simulation and experimental analysis of SiC ceramic grinding mechanism, Ceramics International, Vol.44(2018), pp.12194-12203.

Malkin, S., Grinding Technology, Theory and Applications of Machining with Abrasives(1989), Ellis Horwood Limited, Chichester.

Pang, J.Z., Wu, C.J., Shen, Y.M., Liu, S.Q., Wang, Q.X. and Li, B.Z., Heat Flux Distribution and Temperature Prediction Model for Dry and Wet Cylindrical Plunge Grinding, Proceedings of the Institution of Mechanical Engineers, Part B:Journal of Engineering Manufacture, Vol.233, No.10(2018), DOI:10.1177/0954405418815365.

Tian, L., Fu, Y.C., Xu, J.H., Li, H.Y. and Ding, W.F., The influence of speed on material removal mechanism in high speed grinding with single grit. International Journal of Machine Tools \& Manufacture, Vol.89(2015), pp.192-201.

Wang, C.C.; Fang, Q.H.; Chen, J.B.; Liu, Y.W. and Jin, T., Subsurface damage in high-speed grinding of brittle materials considering kinematic characteristics of the grinding process, International Journal of Advanced Manufacturing Technology, Vol.83 (2016), pp.937-948. 
Wu, C.J., Pang, J.Z., Li, B.Z. and Liang, S.Y., High-speed grinding of HIP-SiC Ceramics on transformation of microscopic features, International Journal of Advanced Manufacturing Technology, Vol.102(2019), pp.1913-1921, DOI:10.1007/s00170-018-03226-4.

Wu, C.J., Li, B.Z., Liu, Y. and Liang, S.Y. Surface roughness modeling for grinding of Silicon Carbide ceramics considering co-existing of brittleness and ductility, International Journal of Mechanical Sciences, Vol.133(2017), pp.167-177.

Wu, C.J., Li, B.Z., Pang, J.Z. and Liang, S.Y., Ductile grinding of silicon carbide in high speed grinding, Journal of Advanced Mechanical Design, Systems, and Manufacturing, Vol.10, No.2(2016).

$\mathrm{Xu}$, H.H.K., Jahanmir, S. and Ives, L.K., Effect of grinding on strength of tetragonal zirconia and zirconia-toughened alumina, Machining Science \& Technology, Vol.1(1997), pp.49-66.

Yue, C.X., Gao, H.N., Liu, X.L., Liang, S.Y. and Wang L.H., A review of chatter vibration research in milling, Chinese Journal of Aeronautics, Vol.32, No.2(2019), pp.215-242.

Yang, M.; Li, C.H.; Zhang, Y.B.; Jia, D.Z.; Zhang, X.P.; Hou, Y.L.; Li, R.Z. and Wang, J., Maximum undeformed equivalent chip thickness for ductile-brittle transition of zirconia ceramics under different lubrication conditions, International Journal of Machine Tools \& Manufacture, Vol.122 (2017), pp.55-65.

Yin, L., Huang, H., Ramesh, K. and Huang, T., High speed versus conventional grinding in high removal rate machining of alumina and alumina-titania, International Journal of Machine Tools \& Manufacture, Vol.45(2005), pp.897-907. 